\title{
Preparation of Organofunctionalized Silica Gel from Polymeric Tributylstannyl Ester of Silicic Acid and Dichlorosilane
}

\author{
Toshio Sugizaki, ${ }^{*}$ Osamu MoriYa, Yoshiyuki Nakamura,** Takeshi Endo, ${ }^{* *}$ \\ Masayuki OiKaWA, ${ }^{* * *}$ and Toshifumi KageYama*** \\ Department of Chemistry, National Defense Academy, Hashirimizu, Yokosuka 239-8686, Japan \\ * Research Laboratory, Lintec Co., Nishiki-cho, Warabi, Saitama 335-0005, Japan \\ ** Research Laboratory of Resources Utilization, Tokyo Institute of Technology, \\ Nagatsuta, Midori-ku, Yokohama 226-8503, Japan \\ *** Department of Chemistry, Faculty of Engineering, Kanto Gakuin University, \\ Mutsuura, Kanazawa-ku, Yokohama 236-8501, Japan
}

(Received February 1, 1999)

\begin{abstract}
KEY WORDS Organofunctionalized Silica Gel / Stannyl Ester of Silicic Acid / Chlorosilane / Metal Exchange Reaction / Solid State Nuclear Magnetic Resonance /
\end{abstract}

In the preceding reports, substitution reactions of tributyltin groups in silica gel and polymeric tributylstannyl ester of silicic acid (PTBS) to silyl groups using monochlorosilanes were shown to proceed readily under mild and neutral conditions. ${ }^{1,2}$ The later work using PTBS is an efficient approach to the preparation of silyl derivatives of silicic acid, which is soluble in usual organic solvents. ${ }^{2}$ Such convenient reactions of PTBS with chlorosilanes seem to widely applicable for the synthesis of organic-inorganic hybrid materials. ${ }^{3-6}$ To obtain hybrid gels, regarded as organically modified silica gels, reactions of PTBS and polyhalosilanes having organofunctional groups should be useful. In such reactions, the polyhalosilane should act as a cross-linking agent to form an inorganic network and supply organofunctional moieties. The use of polyhalosilanes is predicted to enable not only the ready introduction of organofunctional groups but also the control of structure and/or porosity of the resulting gel, which reflects the properties and the size of organic moieties of the polyhalosilanes. This prediction is supported by the several reported works concerning sol-gel process, in which the influence of organic moieties of trialkoxy and bis(trialkoxy)silanes on the structure or the pore sizes of hybrid products prepared is demonstrated. ${ }^{7,8}$ The effects of organic spacers on the structure of inorganic network are argued in the sophisticated study on a bridged silsesquioxane. ${ }^{9}$

Investigation concerning reactions of PTBS with polyhalosilanes was thus made. We describe here the results of fundamental experiments to prepare the organofunctionalized gels 2 from PTBS by using dichlorosilanes $\mathbf{1}$ and analytical information of $\mathbf{2}$ provided by solid state cross polarization/magic angle spinning (CP/MAS) NMR measurement.

\section{EXPERIMENTAL}

All reactions were carried out under argon atmosphere. Benzene for the reactions was refluxed over sodium metal and distilled. Other reagents were used as supplied. Gravimetric analysis was conducted as reported. ${ }^{10}$ IR spectra were recorded on a JASCO FT/IR 230. Gel permeation chromatographic (GPC) analysis was carried out on a TOSOH-HLC-8020 chromatograph equipped with a refractive index detector. Three columns, TSK gel $\mathrm{G} 2500 \mathrm{H}, \mathrm{G} 2000 \mathrm{H}$, and $\mathrm{G} 1000 \mathrm{H}$, were connected in series and tetrahydrofuran (THF) was used as eluent. Calibration was performed using standard polystyrene. Solid-state CP/MAS NMR measurement was carried out with samples in double air bearing $6 \mathrm{~mm}$ rotor of zirconia on a JEOL JNM GX-270 spectrometer operating at $67.8 \mathrm{MHz}$ for ${ }^{13} \mathrm{C}$ and $53.5 \mathrm{MHz}$ for ${ }^{29} \mathrm{Si}$. Magic Angle Spinning was performed at $5.6 \mathrm{kHz}$ spinning rate. The proton $90^{\circ}$ pulse was $5 \mu \mathrm{s}$ for ${ }^{13} \mathrm{C}$ NMR and $4 \mu \mathrm{s}$ for ${ }^{29} \mathrm{Si}$ NMR measurements. ${ }^{29} \mathrm{Si}$ NMR spectra were refered to polydimethylsilane.

\section{Preparation of PTBS}

PTBS was prepared from bis(tributyltin) oxide $\left[\left(\mathrm{Bu}_{3} \mathrm{Sn}\right)_{2} \mathrm{O}\right]$ and water glass according to the altered procedure reported before. ${ }^{10}$ To a solution of water glass

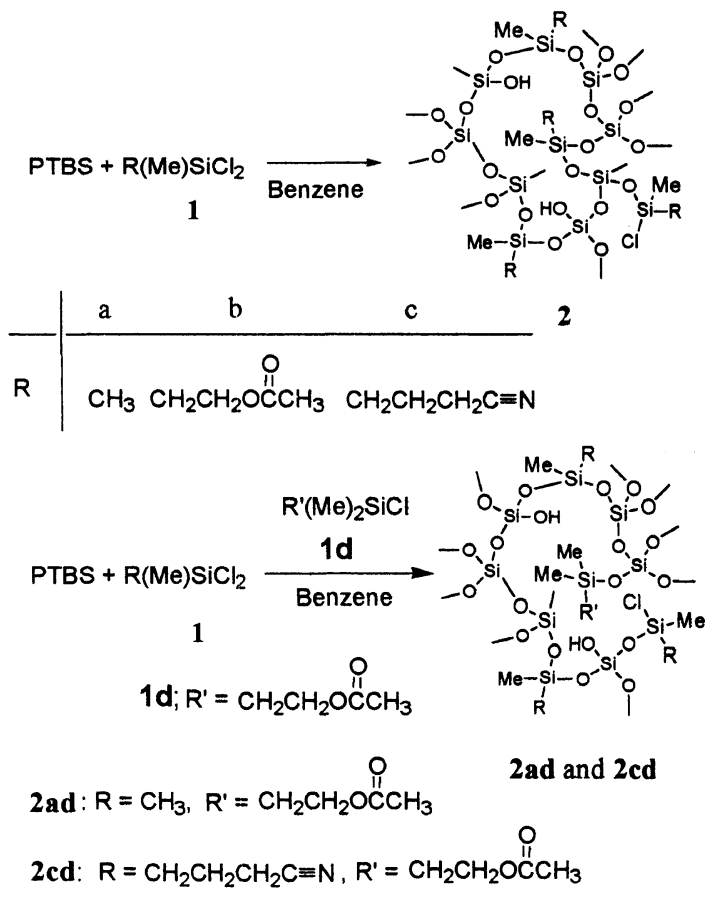

Scheme 1. 
$\left(10 \mathrm{~g}, \mathrm{Na}_{2} \mathrm{O}: 9.4 \mathrm{wt}, \mathrm{SiO}_{2}: 28.5 \mathrm{wt}\right)$ in water $(400 \mathrm{ml})$ and $n$-hexane $(200 \mathrm{ml})$, methanesulfonic acid was added to adjust the $\mathrm{pH}$ of water phase to $c a .4$. $\left(\mathrm{Bu}_{3} \mathrm{Sn}\right)_{2} \mathrm{O}(7.00 \mathrm{~g}$, $11.7 \mathrm{mmol}$ ) was added to the mixture. The mixture was stirred for $6 \mathrm{~h}$ at room temperature and organic phase was separated. After drying over $\mathrm{MgSO}_{4}$ and filtration, the organic solution was evaporated under reduced pressure. Acetone $(30 \mathrm{ml})$ was added to the residual oil and PTBS was obtained as a colorless precipitate after drying at $40^{\circ} \mathrm{C} / 5 \mathrm{mmHg}$ for $12 \mathrm{~h}$. The yield of PTBS $(7.6 \mathrm{~g})$ based on $\mathrm{Si}$ was $96 \%$. The number-average molecular weight $\left(M_{n}\right)$ of PTBS was estimated as 11900 to 14200 (polystyrene standard). The contents of $\mathrm{Sn}$ and $\mathrm{Si}$ determined by gravimetric analysis and elemental analysis were in the range from $2.17 \mathrm{mmol} \mathrm{g}^{-1}$ to 2.23 $\mathrm{mmol} \mathrm{g}^{-1}$ and from $5.26 \mathrm{mmol} \mathrm{g}^{-1}$ to $6.03 \mathrm{mmol} \mathrm{g}^{-1}$, respectively.

\section{General Procedure for Preparation of Organofunction- alized Silica Gel 2}

Reactions of PTBS with dichlorosilane 1 were carried out by mixing the compounds in benzene at room temperature under argon atmosphere. After stirring for $10 \mathrm{~h}$, the resulting gel, which looked like a sol in the reaction mixture, was filtered and washed successively with benzene, diemethylformamide (DMF), methanol, water, acetone, and $n$-hexane. The obtained gel 2 was dried at room temperature under reduced pressure such as $5 \mathrm{mmHg}$.

In a similar manner, a mixture of PTBS and (2acetoxyethyl)dimethylchlorosilane (1d) in benzene was stirred for $6 \mathrm{~h}$ at room temperature and then the dichlorosilane 1a or 1c was added to the reaction mixture. The reaction was continued for further $10 \mathrm{~h}$ at room temperature. The insoluble product in benzene was filtered and treated as mentioned above to obtain the desired gel $\mathbf{2 a d}$ or $\mathbf{2 c d}$.

Those results of the reactions are listed in Table I. Yield was calculated from the content of $\mathrm{Si}$, which was determined by gravimetric analysis, in starting PTBS and 2. In calculating the content of $\mathrm{Si}$ in 2 , that from the incorporated silyl groups was excluded. The content of the silyl groups in $\mathbf{2}$ was estimated from the results of elemental and gravimetric analysis, in which the number of carbons was assigned to the organic groups of the silyl unit and remained tributyl group of tin. In the case of 2ad, the content of the silyl unit having acetate groups from 1d was estimated by IR analysis, in which the calibration curve based on the absorbance at $1720 \mathrm{~cm}^{-1}$ was used. For making the calibration curve between $0 \mathrm{mmol} \mathrm{g}^{-1}$ to $2.26 \mathrm{mmol} \mathrm{g}^{-1}$, mixtures of $\mathbf{2 b}$ and silica gel, which included $0.57,1.13$, and $2.26 \mathrm{mmolg}^{-1}$ of acetate groups, respectively, was used as standard samples.

From PTBS $(0.30 \mathrm{~g}, \mathrm{Si}: 1.80 \mathrm{mmol}, \mathrm{Sn}: 0.65 \mathrm{mmol}$, $\left.M_{n}=12900, M_{w} / M_{n}=1.27\right)$ and dimethyldichlorosilane (1a) $(0.04 \mathrm{~g}, 0.31 \mathrm{mmol}), 2 \mathrm{a}(0.15 \mathrm{~g})$ was obtained (Run 1): IR (KBr) 3435, $2960\left(\mathrm{CH}_{3}\right), 1080 \mathrm{~cm}^{-1} ;{ }^{13} \mathrm{C} \mathrm{CP} / \mathrm{MAS}$ NMR $(67.8 \mathrm{MHz}) \delta-0.63 ;{ }^{29} \mathrm{Si} \mathrm{CP} / \mathrm{MAS}$ NMR $(53.5 \mathrm{MHz}) \delta-110.14,-101.77,-17.17$. Anal. Found: C, $15.15 \%$; H, 3.34\%.

From PTBS $(0.30 \mathrm{~g}, \mathrm{Si}: 1.80 \mathrm{mmol}, \mathrm{Sn}: 0.65 \mathrm{mmol}$, $\left.M_{n}=12900, M_{w} / M_{n}=1.27\right)$ and $1 \mathrm{a}(0.07 \mathrm{~g}, 0.54 \mathrm{mmol})$, 626 2a $(0.13 \mathrm{~g})$ was obtained (Run 2). Anal. Found: C, 7.17\%; $\mathrm{H}, 1.33 \%$.

From PTBS $(0.30 \mathrm{~g}, \mathrm{Si}: 1.80 \mathrm{mmol}, \mathrm{Sn}: 0.65 \mathrm{mmol}$, $\left.M_{n}=12900, M_{w} / M_{n}=1.27\right)$ and $1 \mathrm{a}(0.09 \mathrm{~g}, 0.70 \mathrm{mmol})$, 2a $(0.12 \mathrm{~g})$ was obtained (Run 3). Anal. Found: C, $11.20 \%$; H, $2.37 \%$.

From PTBS $(0.80 \mathrm{~g}$, Si: $4.82 \mathrm{mmol}, \mathrm{Sn}: 1.78 \mathrm{mmol}$, $\left.M_{n}=11900, M_{w} / M_{n}=1.18\right)$ and (2-acetoxyethyl)methyldichlorosilane (1b) $(0.18 \mathrm{~g}, 0.89 \mathrm{mmol}), 2 \mathrm{~b}(0.46 \mathrm{~g})$ was obtained (Run 4): IR (KBr) 3440, $1740(\mathrm{C}=\mathrm{O}), 1270$, $1060,805 \mathrm{~cm}^{-1} ;{ }^{13} \mathrm{C}$ CP/MAS NMR $(67.8 \mathrm{MHz}) \delta$ $-0.40,18.63,20.59,61.52,171.97 ;{ }^{29} \mathrm{Si} \mathrm{CP} / \mathrm{MAS}$ NMR $(53.5 \mathrm{MHz}) \delta-109.23,-100.05,-19.26$. Anal. Found: C, $16.94 \%$; H, $2.80 \%$.

From PTBS $(1.00 \mathrm{~g}$, Si: $5.26 \mathrm{mmol}, \mathrm{Sn}: 2.22 \mathrm{mmol}$, $\left.M_{n}=14000, M_{w} / M_{n}=1.27\right)$ and (3-cyanopropyl)methyldichlorosilane (1c) $(0.32 \mathrm{~g}, 1.76 \mathrm{mmol}), 2 \mathrm{c}(0.56 \mathrm{~g})$ was obtained (Run 5): IR (KBr) $2247(\mathrm{C} \equiv \mathrm{N}), 1082 \mathrm{~cm}^{-1}$; ${ }^{13} \mathrm{C} \mathrm{CP} / \mathrm{MAS}$ NMR $(67.8 \mathrm{MHz}) \delta-1.00,16.21,19.84$, $120.48 ;{ }^{29} \mathrm{Si}$ CP/MAS NMR (53.5 MHz) $\delta-109.69$, $-101.05,-18.08$. Anal. Found: C, 17.60\%; H, $2.92 \%$.

From PTBS $(0.30 \mathrm{~g}$, Si: $1.72 \mathrm{mmol}, \mathrm{Sn}: 0.67 \mathrm{mmol}$, $\left.M_{n}=14200, M_{w} / M_{n}=1.28\right), 1 \mathrm{a}(0.05 \mathrm{~g}, 0.39 \mathrm{mmol})$, and (2-acetoxyethyl)dimethylchlorosilane (1d) (0.04 g, 0.22 mmol), 2ad (0.11 g) was obtained (Run 6): IR (KBr) 2962 , $1745(\mathrm{C}=\mathrm{O}), 1255,1095,845 \mathrm{~cm}^{-1} ;{ }^{13} \mathrm{C} \mathrm{CP} / \mathrm{MAS}$ NMR $(67.8 \mathrm{MHz}) \delta-0.36,18.93,62.19,133.92,172.72 ;{ }^{29} \mathrm{Si}$ CP/MAS NMR (53.5 MHz) $\delta-113.05,-108.69$, $-100.14,-18.99$, 10.49. Anal. Found: C, 15.50\%; H, $3.13 \%$.

From PTBS $(0.30 \mathrm{~g}, \mathrm{Si}: 1.72 \mathrm{mmol}, \mathrm{Sn}: 0.67 \mathrm{mmol}$, $\left.M_{n}=14200, M_{w} / M_{n}=1.28\right) 1 \mathrm{a}(0.05 \mathrm{~g}, 0.39 \mathrm{mmol})$, and 1d $(0.06 \mathrm{~g}, 0.33 \mathrm{mmol}), 2 \mathrm{ad}(0.13 \mathrm{~g})$ was obtained (Run 7). Anal. Found: C, $16.67 \%$; H, 3.02\%.

From PTBS $(0.30 \mathrm{~g}, \mathrm{Si}: 1.72 \mathrm{mmol}, \mathrm{Sn}: 0.67 \mathrm{mmol}$, $\left.M_{n}=14200, M_{w} / M_{n}=1.28\right), 1 \mathrm{a}(0.03 \mathrm{~g}, 0.23 \mathrm{mmol})$, and 1d $(0.12 \mathrm{~g}, 0.66 \mathrm{mmol}), 2 \mathrm{ad}(0.07 \mathrm{~g})$ was obtained (Run 8). Anal. Found: C, $25.87 \% ; \mathrm{H}, 4.62 \%$.

From PTBS $(0.30 \mathrm{~g}, \mathrm{Si}: 1.72 \mathrm{mmol}, \mathrm{Sn}: 0.67 \mathrm{mmol}$, $\left.M_{n}=14200, M_{w} / M_{n}=1.28\right)$ and $1 c(0.07 \mathrm{~g}, 0.38 \mathrm{mmol})$, and 1d $(0.06 \mathrm{~g}, 0.33 \mathrm{mmol}), 2 \mathrm{~cd}(0.11 \mathrm{~g})$ was obtained (Run 9): IR (KBr) $2960\left(\mathrm{CH}_{3}\right), 2348(\mathrm{C} \equiv \mathrm{N}), 1745$ $(\mathrm{C}=\mathrm{O}), 1255,1095,845,758 \mathrm{~cm}^{-1},{ }^{13} \mathrm{C} \mathrm{CP} / \mathrm{MAS}$ NMR $(67.8 \mathrm{MHz}) \delta 0.36,16.58,20.05,62.10,120.48,172.09$; ${ }^{29} \mathrm{Si} \mathrm{CP} / \mathrm{MAS}$ NMR $(53.5 \mathrm{MHz}) \delta-110.51,-101.23$, -18.90 , 10.58. Anal. Found: C, 22.15\%; H, 3.81\%.

\section{RESULTS AND DISCUSSION}

Reaction of PTBS and dichlorosilanes 1 was carried out in benzene solution at room temperature. The formation of a jelly-like mass was observed within $2 \mathrm{~h}$, but the mixture was continuously stirred for $10 \mathrm{~h}$ to make the substitution from tributyltin groups to silyl groups complete. Gel 2 was filtered and washed successively with benzene, DMF, methanol, water, acetone, and $n$-hexane. The incorporation of silyl groups and elimination of tributyltin groups were confirmed by elemental, gravimetric, IR and solid-state NMR. Yields of products 2 were based on the content of Si in PTBS and products $\mathbf{2}$, in which those of $\mathrm{Si}$ attributed to chlorosilanes $\mathbf{1}$ were excluded. The content of incorporated silyl groups was estimated from the number of carbons determined by 
Preparation of Organofunctionalized Silica Gel

Table I. Preparation of organofunctionalized silica gel 2 from PTBS and dichlorosilane 1

\begin{tabular}{|c|c|c|c|c|c|c|}
\hline \multirow[b]{2}{*}{ Run } & \multicolumn{2}{|c|}{ Reaction conditions } & \multicolumn{4}{|c|}{ Organofunctionalized silica gel $\mathbf{2}$} \\
\hline & Chlorosilane & $\mathbf{1} / \mathrm{Sn}$ in PTBS & Content of $\mathrm{Si}^{\mathrm{a}}$ & Content of $\mathrm{Sn}^{\mathrm{a}}$ & Silyl unit ${ }^{\mathbf{b}}$ & Yield $^{\mathrm{c}}$ \\
\hline 1 & $1 \mathbf{a}$ & 0.5 & 12.2 & 0.4 & 2.1 & $84(\mathbf{2 a})$ \\
\hline 2 & $1 \mathbf{a}$ & 0.8 & 15.0 & 0.1 & 2.2 & $86(\mathbf{2 a})$ \\
\hline 3 & 1a & 1.0 & 15.4 & 0.1 & 4.1 & $76(\mathbf{2 a})$ \\
\hline 4 & 1b & 0.8 & 12.5 & 0.1 & 2.8 & $93(\mathbf{2 b})$ \\
\hline 5 & 1c & 0.8 & 11.4 & 0.1 & 2.8 & $92(\mathbf{2 c})$ \\
\hline 6 & $1 \mathrm{a}, 1 \mathrm{~d}$ & $\begin{array}{l}0.6(\mathbf{1 a}) \\
0.3(\mathbf{1 d})\end{array}$ & 13.6 & 0.1 & $\begin{array}{l}2.8(\mathbf{1 a}) \\
0.9(\mathbf{1 d})^{d}\end{array}$ & 81 (2ad) \\
\hline 7 & 1a, 1d & $\begin{array}{l}0.6(\mathbf{l a}) \\
0.5(\mathbf{l d})\end{array}$ & 14.6 & 0.1 & $\begin{array}{l}2.6(\mathbf{1 a}) \\
1.3(\mathbf{1 d})^{\mathrm{d}}\end{array}$ & 87 (2ad) \\
\hline 8 & 1a, $1 d$ & $\begin{array}{l}0.4(\mathbf{1 a}) \\
1.0(\mathbf{1 d})\end{array}$ & 9.6 & 0.2 & $\begin{array}{l}3.8(\mathbf{1 a}) \\
2.3(\mathbf{1 d})^{\mathbf{d}}\end{array}$ & 14 (2ad) \\
\hline
\end{tabular}

${ }^{a}$ Estimated by gravimetric analysis. ${ }^{\mathrm{b}}$ Estimated from elemental analysis. ${ }^{\mathrm{c}}$ Yield was based on content of Si in PTBS and 3. Si due to incorporated silyl groups was excluded. ${ }^{\mathrm{d}}$ Calculated from the intensity of absorbance at $1720 \mathrm{~cm}^{-1}$ in the IR spectra. ${ }^{\mathrm{e}}$ Estimated from elemental analysis.

elemental analysis, which was assigned to the remaining tributyl groups of tin and the organic groups of the silyl unit. The content of tin was determined by gravimetric analysis.

As shown in Table I, gel products 2 were readily obtained in the range from $76 \%$ to $92 \%$ yields by the reactions of PTBS and dichlorosilanes 1 except for Run 8. The use of 0.5 and 0.8 equivalent of 1 a to $\mathrm{Sn}$ in PTBS resulted in the formation of $2 \mathrm{a}$ in $84 \%$ and $86 \%$ yields, respectively (Run 1 and 2). Dimethyldichlorosilane 1a thus possesses enough reactivity to tributylstannyl groups in PTBS, i.e., one silane molecule reacts with two tributylstannyl groups. When an equimolar amount of 1a to $\mathrm{Sn}$ was used for the reaction, the yield of $\mathbf{2 a}$ decreased to $76 \%$ (Run 3). The presence of excess dichlorosilane with the tributyltin group may lead to substitution between one chlorine in the silane $\mathbf{1}$ and one tributyltin group. In such case, a product soluble in organic solvents may be formed as in the reactions using monochlorosilanes. ${ }^{2}$ This may lead to substitution of second chlorine of dichlorosilane 1 becoming slower than that of the first one. The formation of the soluble products or fine particles, containing a large amount of organofunctional moieties, may be the reason why the product is not obtained quantitatively. In a similar manner, gel products $\mathbf{2 b}$ and $\mathbf{2 c}$ having acetoxy groups and cyano groups were obtained in high yields of $93 \%$ and $92 \%$ (Run 4 and 5). The content of the silyl unit in 2c was estimated from elemental analysis, in which the value for nitrogen should coincide with that of the silyl unit. The amounts of eliminated tributyltin groups were estimated by gravimetric analysis for tin. The contents of remained tributyltin groups in products 2 were under $0.4 \mathrm{mmol} \mathrm{g}^{-1}$. The complete elimination and/or removal of tin are thus difficult under the conditions in this work. Although more detailed examination or analytical method is required to clarify the reason, one possible explanation for the incomplete removal is that the eliminated tributyltinchloride is encapsulated in gel $\mathbf{2}$.

IR spectral data demonstrated the presence of functional groups such as acetoxy and cyano groups in $\mathbf{2 b}$

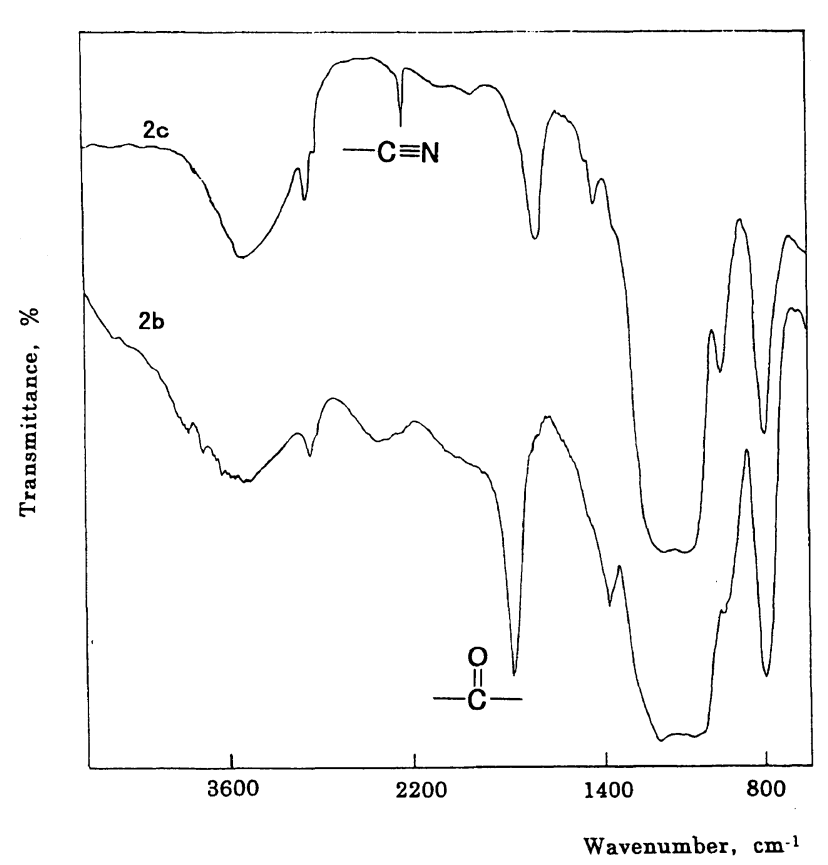

Figure 1. IR spectra of the organofunctionalized gels $\mathbf{2 b}$ and $\mathbf{2 c}$.

and $\mathbf{2 c}$, respectively. In the IR spectra of $\mathbf{2 b}$, the $a b-$ sorption assigned to carbonyl group appeared at 1720 $\mathrm{cm}^{-1}$. The absorption due to cyano group was observed at $2250 \mathrm{~cm}^{-1}$ in the spectrum of $2 \mathrm{c}$. These spectra are shown in Figure 1.

As another application of the reactions to prepare organofunctionalized gels, the following synthetic procedure was examined. Reaction of PTBS and monochlorosilanes was shown in our previous report to afford siloxane derivatives, which are soluble in usual organic solvents. ${ }^{2}$ A combination of such monochlorosilane and dichlorosilane is thought to be effective for the preparation of gel products having various organofunctional groups. The resulting gel seems to possess a wide hydrophobic field, expressed as a steric effect of alkyl groups of the monochlorosilane. This should contribute an efficient chemical reaction and/or a good 


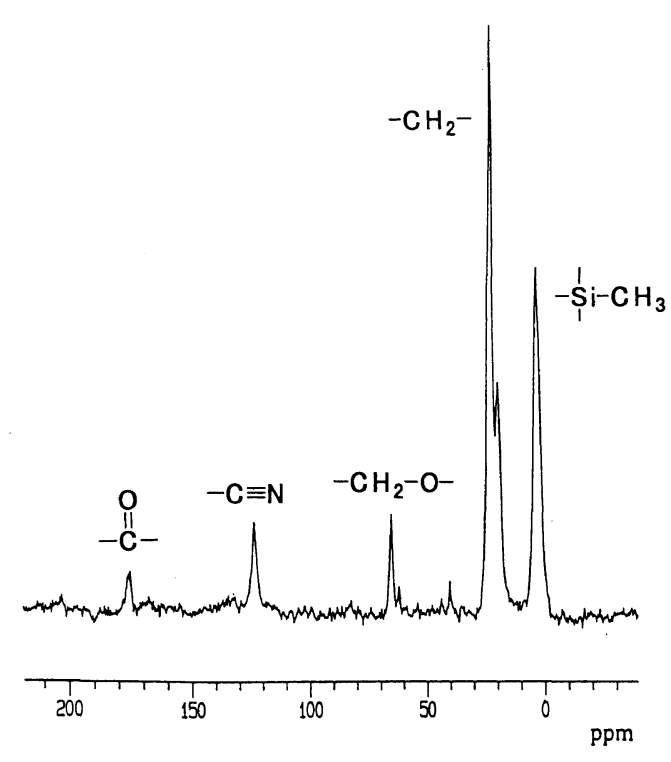

Figure 2. Solid-state ${ }^{13} \mathrm{C} \mathrm{CP} / \mathrm{MAS}$ NMR spectrum of $\mathbf{2 c d}$.

selectivity on absorption. Attempts for preparing such gel were conducted by the use of the monochlorosilane 1d, which have acetoxyethyl group, with 1a or 1c. By consideration of the reactions using monochlorosilanes and PTBS, the complete substitution from tributyltin group to silyl group required at least $3 \mathrm{~h}^{2}$ A jelly-like mass was formed within $2 \mathrm{~h}$ in the reaction of PTBS and dichlorosilane $\mathbf{1 a}-\mathbf{c}$. Dichlorosilanes may thus react more readily with PTBS than monochlorosilanes. Accordingly, monochlorosilane 1d was added to the solution of PTBS at first in the following experiments.

The reaction of PTBS and 1d carried out in benzene at room temperature for $6 \mathrm{~h}$ and dichlorosilane $1 \mathrm{a}$ or $1 \mathrm{c}$ was added to the solution. The reaction was continued for further $10 \mathrm{~h}$ to obtain gel product $\mathbf{2 a d}$ or $\mathbf{2} \mathbf{c d}$. As shown in Table I, gels $\mathbf{2 a d}$ and $\mathbf{2 c d}$ were obtained in moderate yields. On using 1a and 1d, the content of 1d unit in 2ad was estimated by the calibration curve based on the absorbance of $\mathrm{C}=\mathrm{O}$ group in IR spectra. In the case of 2cd, the content of 1c unit was estimated by elemental analysis. The presence of acetoxy and cyano groups in 2cd was indicated by the IR spectrum, in which the absorbances assigned to cyano and carbonyl groups were observed at $2250 \mathrm{~cm}^{-1}$ and $1720 \mathrm{~cm}^{-1}$, respectively. In comparison with the results of experiments using 0.3 equivalent of $1 \mathbf{d}$ and 0.5 equivalent of $\mathbf{1 d}$ to $\mathrm{Sn}$ in PTBS, these amounts were reflected by the content of the unit in the products 2ad (Run 6 and 7). However, reaction using 1.0 equivalent of $1 \mathbf{d}$ to $\mathrm{Sn}$ gave the gel $\mathbf{2 a d}$ in a lower yield such as $14 \%$ (Run 8). This demonstrates that a balance of the amounts of monochlorosilane and dichlorosilane is important and enough stannyl groups must be left for the reaction with dichlorosilane to obtain the gel product effectively. The formation of the multifunctional gel $\mathbf{2} \mathbf{c d}$ demonstrates the usefulness of the procedure using PTBS.

The spectral data of solid-state CP/MAS NMR exhibited the efficient incorporation of the silyl groups into the gels 2 and provided information on the structure of 2 . In the ${ }^{13} \mathrm{C}$ NMR spectrum of $2 a$, the signal assigned to the carbon of methyl group of the silyl unit was observed at $-0.6 \mathrm{ppm}$. Corresponding signals appeared

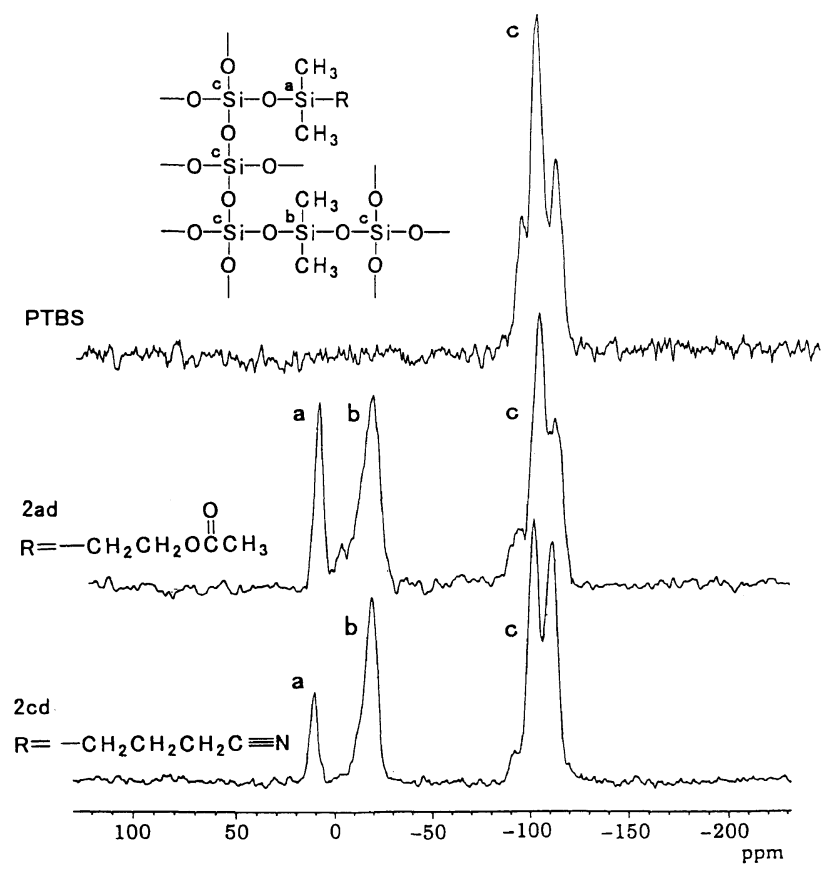

Figure 3. Solid-state ${ }^{29} \mathrm{Si}$ CP/MAS NMR spectra of PTBS, 2ad and 2cd.

at $0.4 \mathrm{ppm}$ and $-1.0 \mathrm{ppm}$ in the cases of $\mathbf{2 b}$ and $\mathbf{2 c}$, respectively. The characteristic signal due to the carbon of ester carbonyl group in $\mathbf{2 b}$ was observed at $c a .172 \mathrm{ppm}$ and that due to cyano group in $2 \mathrm{c}$ was at $c a .120 \mathrm{ppm}$. The existence of carbons of methylenes contained in all gels 2 was revealed by signals from $16 \mathrm{ppm}$ to $20 \mathrm{ppm}$. Signals located at $61.5 \mathrm{ppm}$ were assigned to the carbons next to ester group in $\mathbf{2 b}$. This fundamental information on the chemical shifts of carbons involving $\mathbf{2 a}, \mathbf{2} \mathbf{b}$, and $2 c$ helped understanding of the signals observed in the spectra of $\mathbf{2 a d}$ and $\mathbf{2 c d}$, in which the same functional groups as those in $\mathbf{2 b}$ and $\mathbf{2 c}$ were introduced. In the ${ }^{13} \mathrm{C}$ NMR spectrum of $\mathbf{2 a d}$, a signal assigned to the carbon of carbonyl group was observed at $c a .172 \mathrm{ppm}$ and the next one to the ester group at $62.2 \mathrm{ppm}$. The signals for carbon of methyl and methylene attached to Si appeared at $0.4 \mathrm{ppm}$ and $18.9 \mathrm{ppm}$, respectively. Signals for carbons in the spectrum of 2cd showed reasonable chemical shifts. The solid-state ${ }^{13} \mathrm{C}$ NMR spectrum of $\mathbf{2} \mathbf{c d}$ is shown in Figure 2.

The presence of speculated constituents in 2 was confirmed by the solid-state ${ }^{29} \mathrm{Si}$ NMR spectra. In all spectra of ${ }^{29} \mathrm{Si}$ NMR of 2 , signals assigned to $\mathrm{Si}$ which constructed the inorganic network were found in the field from $-118 \mathrm{ppm}$ to $-101 \mathrm{ppm}$. The chemical shifts of these signals are in the same region to those reported as $Q^{3}$ and $Q^{4} .^{11,12} Q^{2}$ signals at -93.5 and $-95.0 \mathrm{ppm}$ observed in PTBS disappeared in these spectra. This suggests that two stannyloxy groups bonded to one $\mathrm{Si}$ in PTBS are completely substituted to silyloxy groups. In the spectra of $2 \mathbf{a}$, the signal observed at $-21.3 \mathrm{ppm}$ was assigned to $\mathrm{Si}$ of dimethylsilyl group. The corresponding $\mathrm{Si}$ of $2 \mathrm{c}$ unit appeared at $-18.1 \mathrm{ppm}$ and that of $\mathbf{2 b}$ at $-20.1 \mathrm{ppm}$. These signals were found in the spectra of $\mathbf{2 a d}$ and $\mathbf{2 c d}$. The signal newly observed at $c a .10 .5 \mathrm{ppm}$ in the spectra of $\mathbf{2 a d}$ and $\mathbf{2} \mathbf{c d}$ represented the existence of $\mathrm{Si}$ of $\mathbf{1 d}$ unit. $^{13}$ The signal for $\mathrm{Si}$ of 
trimethylsilyl group is reported at $14.0 \mathrm{ppm}$. Accordingly, the signal at $10.5 \mathrm{ppm}$ is thought assignable to $\mathrm{Si}$ of the trialkylated silyl group of 1d. These solid-state ${ }^{29} \mathrm{Si}$ NMR spectra of PTBS, 2ad, and 2ed are shown in Figure 3.

The organofunctionalized silica gel $\mathbf{2}$ was prepared from the reaction of PTBS and chlorosilanes $\mathbf{1}$, in which dichlorosilanes $\mathbf{1 a}-\mathbf{c}$ were found useful cross-linking agents. The efficient incorporation of the silyl unit into the gels 2 was indicated by solid-state NMR measurement. Further investigation on the properties and synthetic applications of the gels are in progress.

\section{REFERENCES}

1. T. Sugizaki, T. Kageyama, and O. Moriya, J. Ceram. Soc., 106, 727 (1998).

2. T. Sugizaki, M. Oikawa, O. Moriya, and T. Kageyama, J. Polym. Sci., Polym. Chem. Ed., in press.
3. C. Sanchez and F. Ribot, New J. Chem., 18, 1007 (1994).

4. R. Kroker, M. Schneider, and R. Hamann, Prog. Org. Coatings, 1 (1972).

5. G. Philip, J. Non-Cryst. Solids, 63, 283 (1984).

6. C. A. Fyfe and J. Niu, Macromolecules, 28, 3894 (1995).

7. J. F. Brown, Jr. and L. H. Vogt, Jr., J. Am. Chem. Soc., 87, 4313 (1965).

8. K. J. Shea, D. A. Loy, and O. Webster, J. Am. Chem. Soc., 114 6700 (1992).

9. C. Zhang, F. Babonneau, C. Bonhomme, R. M. Laine, C. L. Soles, H. A. Hristov, and A. F. Yee, J. Am. Chem. Soc., 120, 8380 (1998).

10. T. Iida, T. Sugizaki, T. Kageyama, and O. Moriya, J. Polym. Sci., Polym. Chem. Ed., 36, 655 (1998).

11. E. Lippmaa, M. Magi, A. Samoson, G. Engelhardt, and A. R. Grimmer, J. Am. Chem. Soc., 102, 4889 (1980).

12. H. A. Frank, J. D. Bolt, S. M. de B. Costa, and K. Sauer, J. Am Chem. Soc., 102, 4893 (1980).

13. D. Derouet, S. Forgead, J-C. Brosse, J. Emery, and J-Y. Buzare, J. Polym. Sci., Polym. Chem. Ed., 36, 437 (1998). 